\title{
Coagulation of humic waters for diffused pollution control and the influence of coagulant type on DOC fractions removed
}

Elisangela Heiderscheidt ${ }^{\text {a* }}$, Tiina Leiviskä ${ }^{\mathrm{b}}$, Bjørn Kløve ${ }^{\mathrm{a}}$

${ }^{a}$ Water Resources and Environmental Engineering, Faculty of Technology, 90014 University of Oulu, Finland.

${ }^{b}$ Chemical Process Engineering, Faculty of Technology, 90014 University of Oulu, Finland.

* Corresponding author: Water Resources and Environmental Engineering, Faculty of Technology, 90014 University of Oulu, Finland. Phone: $+358 \quad(0) 85534502 \quad e$ mail:elisangela.heiderscheidt@oulu.fi.

\begin{abstract}
:
This study examined the suitability of organic coagulants for treatment of typically humic peat extraction runoff water by comparing their performance with that of ferric sulphate (FS). The influence of coagulant type on dissolved organic carbon (DOC) fractions removed was analysed in detail using LC-OCD-OND (size exclusion liquid chromatography coupled with organic carbon and organic nitrogen detection) fractionation techniques. In general, lower coagulant dosage was needed under acidic ( $\mathrm{pH} 4.5)$ than neutral (pH 6.5) conditions. Chitosan (Chit) and poly(diallyldimethyl) ammonium chloride (pDMAC) required significantly lower dosage (40-55\%) than FS for acceptable purification, while a tannin-based coagulant (Tan2) required substantially higher dosage (55-75\%) independent of water pH. FS demonstrated the best removal of DOC $(<81 \%)$ and phosphorus $(<93 \%)$ followed by pDMAC, while Chit and Tan2 achieved the highest removal of suspended solids (SS) $(<58 \%)$, with flocs formed by Tan2 presenting the best settling properties. Higher molecular weight (MW) DOC fractions were more efficiently removed by all coagulants, with FS being the most efficient (biopolymers $69 \%$ and humic substances 91\%), followed by Tan2. FS also displayed satisfactory removal of lower MW fractions (building blocks $\sim 46 \%$ and low MW neutrals 62\%). Overall, FS was the best performing coagulant. Nevertheless, the organic polymers demonstrated satisfactory overall performance, achieving purification rates mostly inside the requirements set by Finnish environmental authorities.
\end{abstract}

Keywords: organic polymers, coagulation, DOC fractionation, LC-OCD-OND, organic nitrogen. 


\section{Introduction}

Finnish environmental authorities oblige the country's peat extraction industry to purify runoff water from extraction sites and consider chemical treatment to be one of the best available technologies for this purpose (Finnish Ministry of the Environment, 2015). Cost-effective application of chemical treatment for diffuse pollution control is challenging due to the need for simple and low-cost facilities (resulting in low process control) and the recognised variations in runoff water quality $(\mathrm{pH}$, dissolved organic carbon (DOC) and suspended solids (SS) concentration), temperature and discharge (Heiderscheidt, et al., 2015). Significant fluctuations in purification efficiency and increased acidity, metal and sulphate concentrations have been observed at Finnish peat extraction sites where ferric sulphate (FS) is applied (Finnish Environmental Institute, 2015). Evaluation of alternative coagulants for the treatment of this typically humic water can provide solutions which can enable the purification process to better cope with existing conditions, while also decreasing performance variability and the negative environmental impacts related to the use of metal salts coagulants.

Synthetic organic polymers have been widely used as flocculants and sludge dewatering aids chemicals (Gregory and Bolto, 2007) in the purification of water and wastewaters from various sources. Nevertheless, cationic polymers such as poly(diallyldimethyl) ammonium chloride (pDMAC) with high charge density (CD) have also been successfully applied as primary coagulants (Bolto et al., 1999; Nozaic et al., 2001). Synthetic organic polymers do not consume alkalinity and have been found to display lower sensitivity to variations in water quality, to require lower dosage than metal salt coagulants and to produce less sludge with better dewatering characteristics (Gregory and Bolto, 2007). Some of the drawbacks of synthetic organic polymers are their low biodegradability, high cost and toxicity with potential harmful impacts on human health (Letterman and Pero, 1990) and on the aquatic ecosystem (Harford et al., 2011). The need for less toxic and more environmentally friendly water treatment products has prompted research into natural polymers (biopolymers). These products are naturally produced or extracted from animals, plant tissues or microorganisms and have benefits such as nontoxicity and high biodegradability (Gregory and Bolto, 2007, Oladoja, 2015). Among the currently developed and commercially available biopolymers are chitosan and tannin-based products. Chitosan is a linear copolymer of d-glucosamine and $\mathrm{N}$-acetyl-d-glucosamine produced by the alkaline deacetylation of chitin, a biopolymer extracted from shellfish sources. Chitosan is virtually insoluble in water under neutral conditions, but it can be dissolved in acid solutions such as acetic and hydrochloric acid (Renault et al., 2009). Water-soluble modified chitosan polymers have been developed by e.g. controlled deacetylation and chemical modification methods (Kurita, 1991; Holme and Perlin, 1997). Several studies have evaluated the use of acid-soluble chitosan for the removal of turbidity and natural 
organic matter (NOM) (Bratskaya et al., 2004; Guibal et al., 2006; Renault et al., 2009) while fewer studies have evaluated water-soluble products (Yang et al., 2011; Chen et al., 2015). Overall, they have reported advantages such as lower dosage requirements, lower metal residuals and lower (less toxic) sludge production compared with metal salts (Guibal et al., 2006; Renault et al., 2009; Ang et al., 2015; Chen et al., 2015; Oladoja, 2015). Tannin is a general name given to large polyphenol compounds obtained from natural materials, such as organic extracts from tree bark and wood. Tannin-derived cationic coagulants have been synthesised from several tannin feed stocks (e.g. Acacia, Schinopsis and Pinus) through relatively simple cationization procedures which involve Mannich base reactions (Tramontini and Angiolini, 1994). Tannin-based coagulants have also been successfully tested for turbidity and organic matter removal (Graham et al., 2008; Sánchez-Martín et al., 2010).

Discharge limits for peat extraction runoff water in Finland are provided in a case-by-case base via environmental permits issued by environmental authorities. Expected removal efficiency for SS and nutrients is generally high (SS 50\%, total nitrogen 30-50\% and total phosphorous 60-90\%) (Wichmann, 2015; Finnish Ministry of the Environment, 2015). The removal of organic matter (chemical oxygen demand (COD) 60-80\%) has also received especial attention in recent years due to observed trends for increased DOC concentration in rivers and lakes (Vuorenmaa et al., 2006; Finnish Ministry of the Environment, 2015). Higher DOC concentration not only affect the aquatic ecosystem (Evans, et al., 2005), but also the treatability of the water; requiring higher coagulant doses increasing the risk of formation of disinfection by-products (DBP) (Matilainen et al., 2010). Coagulation-flocculation is an effective method for DOC removal with the higher molecular weight (MW) more hydrophobic fractions reported as being more efficiently removed (Bolto et al., 1999; Wang et al., 2013). The development of improved size-exclusion liquid chromatography techniques coupled with organic carbon (OC) and organic nitrogen (ON) detection (LC-OCD-OND, fully described in Huber at al., 2011) has enabled more detailed characterization of DOC contained in water samples. Thus, permitting a more effective investigation of the fractions removed by coagulation-flocculation. This improved technique has been used in the evaluation of DOC removal by metal salt coagulants from sea water (Jeong et al., 2014) and surface water (Slavik et al., 2014). To our knowledge, the influence of coagulant type on the removal of different DOC fractions has not previously been studied using the LC-OCD-OND technique.

The aim of this study was thus to investigate the suitability of organic polymers for the purification of peat extraction runoff by comparing their performance to that achieved by the normally used metal salt coagulant ferric sulphate (FS). A further aim was to evaluate the influence of coagulant type on removal of DOC fractions via fractionation analysis using the LC-OCD-OND technique. The effects of initial water $\mathrm{pH}$ on coagulant dosage and DOC removal were also studied. Natural water samples were used 
and five commercially available coagulants were tested. The synthetic organic polymer pDMAC and the iron based coagulant FS were selected based on results from previous studies (Heiderscheidt et al., 2016). According to commercial availability, two tannin-based (Tan1 and Tan2) and one chitosan (Chit) natural biopolymers were selected.

\section{Materials and methods}

The jar test procedure was applied to simulate the various stages of the chemical purification process for the natural runoff water samples. Research methodology was designed to evaluate the: 1) Dosage requirements of selected coagulants for initial water $\mathrm{pH} 4.5$ and adjusted $\mathrm{pH} 6.5$; 2) purification efficiency and settling characteristics of flocs formed in samples with initial water $\mathrm{pH} 4.5$ and 6.5; and 3) characteristics and concentrations of different organic matter fractions contained in the runoff water samples before and after the chemical purification process.

\subsection{Characteristics of the water}

Water samples were collected (350 L, in 10 x 35-L containers) in July 2014 from a peat extraction site managed by Vapo Oy in the municipality of Vihanti, Finland. A sub-sample of $140 \mathrm{~L}$ was created by increasing the initial $\mathrm{pH}$ of the runoff water from 4.5 to 6.5 using a $0.5 \mathrm{M}$ solution of sodium hydroxide $(\mathrm{NaOH})$. Sample and sub-samples were stored at 5-10 ${ }^{\circ} \mathrm{C}$ for the 5-week testing period, during which a series of water quality analyses were periodically performed. The water quality characteristics of the collected sample (Table 1) as well as the $\mathrm{pH}$ variation applied (4.5-6.5) are typical of peat extraction runoff water (Heiderscheidt et al., 2015), thus the sample is representative of real operational conditions.

Water quality analyses were conducted at our in-house laboratory using standard methods: Suspended SS: (1.2 $\mu$ m filtration), SFS-EN 872:2005; turbidity: EN 27027:1994 (Hatch Ratio/XR Turbidity meter); colour: ISO 7887:1994 (Lovibond Nessleriser Daylight 2000); and pH: SFS-EN 13037:1994 (WTW Universal meter). Charge quantity $(\mathrm{Cq})$ measurements were performed using the Mütek particle charge detector PCD 03 PH (Mütek Analytic GmbH, Germany) following the equipment manual. The method measures the total surface charge contained in the suspension using the streaming current principle. The samples were titrated using either cationic or anionic polyelectrolyte $(0.001 \mathrm{eq} / \mathrm{L})$ until the charge of the sample was neutralised. The $\mathrm{Cq}$ value $(\mathrm{eq} / \mathrm{L})$ of the sample was then determined based on the concentration and amount of polymer required for the neutralisation of fixed volume $(10 \mathrm{~mL})$ samples. Zeta $(\zeta)$ potential measurements were performed using the Delsa Nano C Particle Analyser (detection size range between $0.6 \mathrm{~nm}-7 \mathrm{~mm}$ ). The performance of the equipment was checked using a mobility control (Otsuka Electronics Co, Ltd.) containing polystyrene latex particles. Ultraviolet (UV) 
absorbance at $254 \mathrm{~nm}$ (UV 254 abs.) was measured using the UV 1800 spectrophotometer equipment (Shimadzu, Japan) following the manufacturer's instructions $(0.45 \mu \mathrm{m}$ filtration). DOC analyses were performed using the Sievers 900 Portable TOC Analyser. Samples were filtered $(0.45 \mu \mathrm{m})$ prior to analyses and the manufacturer's instructions were followed. Specific UV absorbance (SUVA) was determined as follow: $\mathrm{SUVA}=\mathrm{UV}_{254} \mathrm{abs} / \mathrm{DOC}(\mathrm{L} / \mathrm{mg}-\mathrm{m})$.

Water quality analyses performed by the Finnish Environment Institute laboratory (Oulu, Finland) and standard methods applied: Total phosphorus (tot-P): SFS-EN ISO 6878:2004 FIA technique; phosphate phosphorus ( $\left.\mathrm{PO}_{4}-\mathrm{P}\right)$ : SFS-EN ISO 6878:2004, FIA technique; Total iron (Fe): in-house method IC207 and IC209, microwave oven combustion preparation, ICP-OES technique ISO 11885:2007; sulphate $\left(\mathrm{SO}_{4}{ }^{2-}\right)$ : ISO 10304-1:2007; total nitrogen (tot-N): SFS-EN ISO 11905-1:1998; and alkalinity: in-house method IC010 potentiometric method.

Table 1 - Characteristics of runoff water sample with $\mathrm{pH} 4.5$ and of sub-sample with increased $\mathrm{pH}$ 6.5.

\begin{tabular}{lcccc}
\hline $\begin{array}{l}\text { Water quality } \\
\text { parameters }\end{array}$ & \multicolumn{2}{c}{ Natural sample pH } & & \multicolumn{2}{c}{ Increased pH sub-sample } \\
& $\begin{array}{c}\text { Mean } \\
\pm \text { Std. dev. }\end{array}$ & $\begin{array}{c}\text { Number of } \\
\text { analyses }(\mathbf{n})\end{array}$ & $\begin{array}{c}\text { Mean } \\
\pm \text { Std. dev. }\end{array}$ & $\begin{array}{c}\text { Number of } \\
\text { analyses }(\mathbf{n})\end{array}$ \\
\hline $\mathrm{DOC}(\mathrm{mg} / \mathrm{L})$ & $76.2 \pm 2.0$ & 2 & $80.8 \pm 1.1$ & 2 \\
Colour $(\mathrm{mg}$ Pt/L) & $750 \pm 0$ & 8 & $728 \pm 32$ & 9 \\
$\mathrm{SS}(\mathrm{mg} / \mathrm{L})$ & $7.5 \pm 2.5$ & 3 & $5.9 \pm 2.0$ & 2 \\
Turbidity $(\mathrm{NTU})$ & $6.9 \pm 0.2$ & 8 & $6.4 \pm 0.3$ & 9 \\
tot-P $(\mu \mathrm{g} / \mathrm{L})$ & $107.0 \pm 18.4$ & 2 & $115.0 \pm 7.1$ & 2 \\
$\mathrm{PO}-\mathrm{P}(\mu \mathrm{g} / \mathrm{L})$ & $34.5 \pm 3.5$ & 2 & $33.0 \pm 0.0$ & 2 \\
tot-N $(\mu \mathrm{g} / \mathrm{L})$ & $2300 \pm 141$ & 2 & $2200 \pm 424$ & 2 \\
$\mathrm{Fe}(\mu \mathrm{g} / \mathrm{L})$ & $4400 \pm 141$ & 2 & $4450 \pm 71$ & 2 \\
$\mathrm{SO}{ }_{4}^{2-}(\mathrm{mg} / \mathrm{L})$ & $4.9 \pm 0.2$ & 2 & $4.5 \pm 0.1$ & 2 \\
$\mathrm{Cq}(\mu \mathrm{eq} / \mathrm{L})$ & $-242 \pm 5$ & 5 & $-390 \pm 29$ & 5 \\
$\zeta-$ potential $(\mathrm{mV})$ & $-19.4 \pm 0.3$ & 2 & $-23.1 \pm 0.1$ & 2 \\
$\mathrm{SUVA}(\mathrm{L} / \mathrm{mg}-\mathrm{m})$ & $3.8 \pm 0.1$ & 2 & $3.9 \pm 0.1$ & 2 \\
$\mathrm{Alkalinity}(\mathrm{mmol} / \mathrm{L})$ & $0.03 \pm 0.01$ & 2 & $0.38 \pm 0.05$ & 2 \\
pH & $4.45-4.52$ & 8 & $6.52-6.70$ & 9 \\
\hline
\end{tabular}

Organic matter fractionation analyses were performed by DOC-Labor (Eisenbahnstrasse, Germany) using the LC-OCD-OND (Liquid Chromatography - Organic Carbon Detection - Organic Nitrogen Detection) methodology which is fully described in Huber et al., (2011). The compilation of the used techniques (chromatographic column, UV detection (UVD), organic carbon detection (OCD) and organic nitrogen detection (OND)) allowed the authors to separate NOM into fractions according to size and chemical behaviour. The method separated the DOC into hydrophobic organic carbon (HOC) and chromatographic dissolved organic carbon (CDOC). The CDOC is the organic carbon (OC) value obtained by area integration of the total chromatogram. HOC was determined as the difference between DOC and CDOC and thus all OC retained in the chromatography column was defined as 'hydrophobic' 
in this context. The CDOC fraction (described as having a hydrophilic nature) was further segregated into the following fractions: biopolymers (polysaccharides, proteins and amino sugars, MW>10000 g/mol); humic substances (HS; MW 500-1000 g/mol); building blocks (breakdown products of HS; MW 300-500 g/mol); low MW (LMW) neutrals such as alcohols, aldehydes, ketones, sugars (MW<350 $\mathrm{g} / \mathrm{mol}$ ); and LMW acids (MW<350 g/mol). For a detailed description of the fractionation process and properties of the specific fraction please refer to Huber et al. (2011).

\subsection{Characteristics of tested coagulants}

The coagulants tested (Table 2) were: ferric sulphate (FS), synthetic organic polymer poly(diallyldimethyl) ammonium chloride (pDMAC), chitosan biopolymer (Chit), tannin-based biopolymer 1 (Tan1) and tannin-based biopolymer 2 (Tan2). FS, pDMAC, Tan1 and Tan2 stock solution (20 $\mathrm{mg} / \mathrm{mL}$ product) was prepared by dilution of the commercially supplied liquid products with deionised water. Chitosan stock solution $(5 \mathrm{mg} / \mathrm{mL})$ was prepared by dissolving the solid product $(2.5$ $\mathrm{g}$ ) in a solution containing acetic acid $100 \%(5 \mathrm{~mL})$ and deionised waster $(492.5 \mathrm{~mL})$ and stirring the mixture using a magnetic mixer $(200 \mathrm{rpm})$ for a period of 4 hours. Stock solutions of all coagulants were freshly prepared every 2 days. The reported coagulant dosage refer to the coagulant 'effective dosage' calculated from the volume dosed and the percentage of dry solids (active ingredient) contained in the supplied products (Table 2). Data on the MW of pDMAC and Chit were provided by the suppliers. The average MW of the tannin based polymers was determined by an out-source laboratory at the Process and Chemistry Centre, Åbo Academy University, Turku - Finland. The measurements were made using High Pressure Size Exclusion Chromatography (HPSEC) columns coupled with a multiangle-laser-lightscattering detector and a refractive index detector. A full description of the equipment and methodology used is provided in Song et al. (2008). Data on the CD of pDMAC was supplied by the manufacturer, while the $\mathrm{CD}$ of the natural polymers was determined at the in-house laboratory using the Mütek particle charge detector PCD 03 PH (Mütek Analytic GmbH, Germany). Polymers solutions of varying concentrations were prepared and $\mathrm{Cq}$ measurements were performed following the methodology described above. The CD of the polymers (eq/g) was calculated based on the concentration of the coagulant solutions. 
Table 2 - Properties of coagulants tested.

\begin{tabular}{|c|c|c|c|c|}
\hline Organic coagulant & $\begin{array}{c}\text { Molecular Weight } \\
(\mathrm{g} / \mathrm{mol})\end{array}$ & $\begin{array}{l}\text { Dry solids } \\
(\%)\end{array}$ & $\begin{array}{c}\text { Charge density } \\
\text { (meq/g of dry solids) }\end{array}$ & Supplier \\
\hline $\begin{array}{l}\text { PolyDADMAC } \\
\text { Synthetic - liquid } \\
\text { Referred to as: pDMAC }\end{array}$ & $\begin{array}{l}200000 \\
\text { Supplied }\end{array}$ & 20 & $\begin{array}{c}6 \\
\text { Supplied }\end{array}$ & $\begin{array}{l}\text { Kemira Oyj } \\
\text { Kemwater } \\
\text { Finland }\end{array}$ \\
\hline $\begin{array}{l}\text { Tannin-based } \\
\text { Natural - liquid } \\
\text { Referred to as: Tan1 }\end{array}$ & $\begin{array}{c}300 \\
\text { Measured }\end{array}$ & 25 & $\begin{array}{c}2.3 \\
\text { Measured }\end{array}$ & $\begin{array}{c}\text { Grove } \\
\text { Advanced } \\
\text { Chemicals } \\
\text { Portugal }\end{array}$ \\
\hline $\begin{array}{l}\text { Tannin-based } \\
\text { Natural - liquid } \\
\text { Referred to as: Tan2 }\end{array}$ & $\begin{array}{c}1800 \\
\text { Measured }\end{array}$ & 25 & $\begin{array}{c}2.2 \\
\text { Measured }\end{array}$ & $\begin{array}{c}\text { Grove } \\
\text { Advanced } \\
\text { Chemicals } \\
\text { Portugal }\end{array}$ \\
\hline $\begin{array}{l}\text { Chitosan } \\
\text { Natural - solid } \\
\text { Referred to as: Chit }\end{array}$ & $\begin{array}{c}\text { 310000-375000 } \\
\text { Supplied }\end{array}$ & 100 & $\begin{array}{c}5.2 \\
\text { Measured }\end{array}$ & $\begin{array}{l}\text { Sigma } \\
\text { Aldrich } \\
\text { USA }\end{array}$ \\
\hline Metal salt coagulant & $\begin{array}{l}\text { Density } \\
\left(\mathrm{kg} / \mathrm{m}^{3}\right)\end{array}$ & $\begin{array}{c}\text { Dry solids } \\
(\%)\end{array}$ & $\begin{array}{c}\text { Active substance } \\
(\mathrm{mol} / \mathrm{kg})\end{array}$ & Supplier \\
\hline $\begin{array}{l}\text { Ferric sulphate } \\
{\left[\mathrm{Fe}_{2}\left(\mathrm{SO}_{4}\right)_{3} \cdot \mathrm{nH}_{2} \mathrm{O}\right]} \\
\text { Liquid } \\
\text { Referred to as: FS }\end{array}$ & 1550 & 42 & 2.1 & $\begin{array}{l}\text { Kemira Oyj } \\
\text { Kemwater } \\
\text { Finland }\end{array}$ \\
\hline
\end{tabular}

\subsection{Experimental procedure}

Jar tests were performed using the six (1-L) jar programmable paddle stirrer equipment Flocculator 2000 (Kemira Kemwater). Mixing parameters applied were: $300 \mathrm{rpm}$ for $10 \mathrm{sec}$ followed by $50 \mathrm{rpm}$ for 15 min and 30 min of sedimentation. The coagulant doses required was evaluated by sequential addition of increasing dose to 1-L samples ( $\mathrm{pH} 4.5$ and 6.5). The performance of individual coagulants was first evaluated based on colour, turbidity, $\mathrm{Cq}, \zeta$-potential and $\mathrm{pH}$ values observed in the treated samples (two replicates). The doses which provided the best removal of colour and turbidity were identified as the optimum dosage of the coagulants. Four coagulants were selected for the second stage of testing: FS, pDMAC, Chit and the best performing tannin-based biopolymer. For the evaluation of purification efficiency at each water $\mathrm{pH}$ (4.5 and 6.5), samples of the water purified with the optimum dosages (two replicates) were analysed for: DOC, tot-P, $\mathrm{PO}_{4}-\mathrm{P}$, tot-N, Fe, $\mathrm{SO}_{4}{ }^{2-}, \mathrm{SS}$, alkalinity colour, turbidity, $\mathrm{Cq}$, $\zeta$-potential $\mathrm{UV}_{254}$ abs. and $\mathrm{pH}$. Furthermore, the characteristics of the DOC contained in the samples were investigated using the LC-OCD-OND technique. The settling characteristics of flocs formed by the optimum dosages of the coagulants was investigated using the jar test equipment following the method outlined in Bratby (2006). Turbidity measurements were performed on 30-mL samples collected at constant jar depth ( $8 \mathrm{~cm}$ from the bottom) and at pre-determined time intervals $(1,2,3,4,6,8,11,14$, 
17 and $25 \mathrm{~min}$ ) during the sedimentation phase of the purification process (two replicates for each water pH, i.e. 4.5 and 6.5).

\section{Results and discussion}

\subsection{Dosage required and the influence of $\mathrm{pH}$ on the coagulation process}

The initial $\mathrm{pH}$ of raw water had a significant influence on the coagulant dosage required for satisfactory removal of colour and turbidity, with lower dosages needed for samples with lower initial pH (Fig. 1). In general, Chit and pDMAC required significantly lower dosage (40-55\%) than FS, while the tanninbased coagulants required substantially higher (55-125\%) dosage. Within the optimum dosage range, the removal of colour and turbidity by FS was higher for water samples with higher initial pH (Fig.1a and $1 \mathrm{~b}$ ), while pDMAC achieved better removal rates in lower $\mathrm{pH}$ conditions. Similar removal rates were observed at both $\mathrm{pH}$ levels for Chit and the tannin-based coagulants. The optimum coagulant dosage identified was: i) Initial raw water pH 4.5: FS $71 \mathrm{mg} / \mathrm{L}$, pDMAC $32 \mathrm{mg} / \mathrm{L}$, Tan1 $120 \mathrm{mg} / \mathrm{L}$, Tan2 110 mg/L, Chit 40 mg/L; ii) Adjusted raw water pH 6.5: FS 80 mg/L, pDMAC 52 mg/L, Tan1 180 $\mathrm{mg} / \mathrm{L}$, Tan2 $170 \mathrm{mg} / \mathrm{L}$, Chit $50 \mathrm{mg} / \mathrm{L}$. Due to the low alkalinity (low buffering capacity) of the raw water samples (Table 1), the addition of FS decreased the $\mathrm{pH}$ of the water substantially (Fig. 1a and 1b). Chit (Fig. $1 \mathrm{i}$ and $1 \mathrm{j}$ ) and the tannin-based coagulants (Fig. 1e - 1h) also had an impact on the water $\mathrm{pH}$, although less significant. Regarding the performance of the tannin-based products, Tan 2 showed better removal of colour and turbidity at lower dosages than Tan1. Therefore, Tan2 was selected for the next stage of testing together with FS, pDMAC and Chit. 
Initial $\mathrm{pH} 4.5$
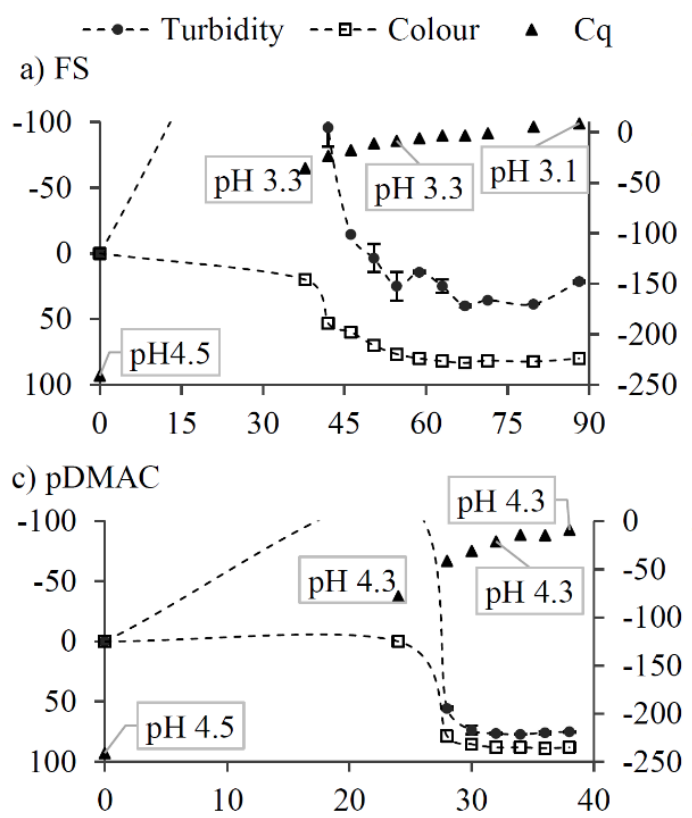

b) FS

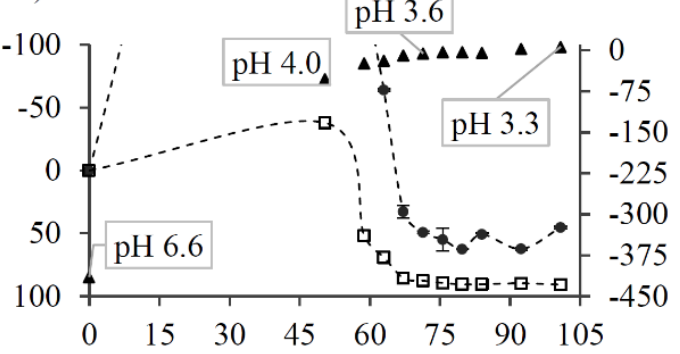

d) pDMAC

pH 6.2
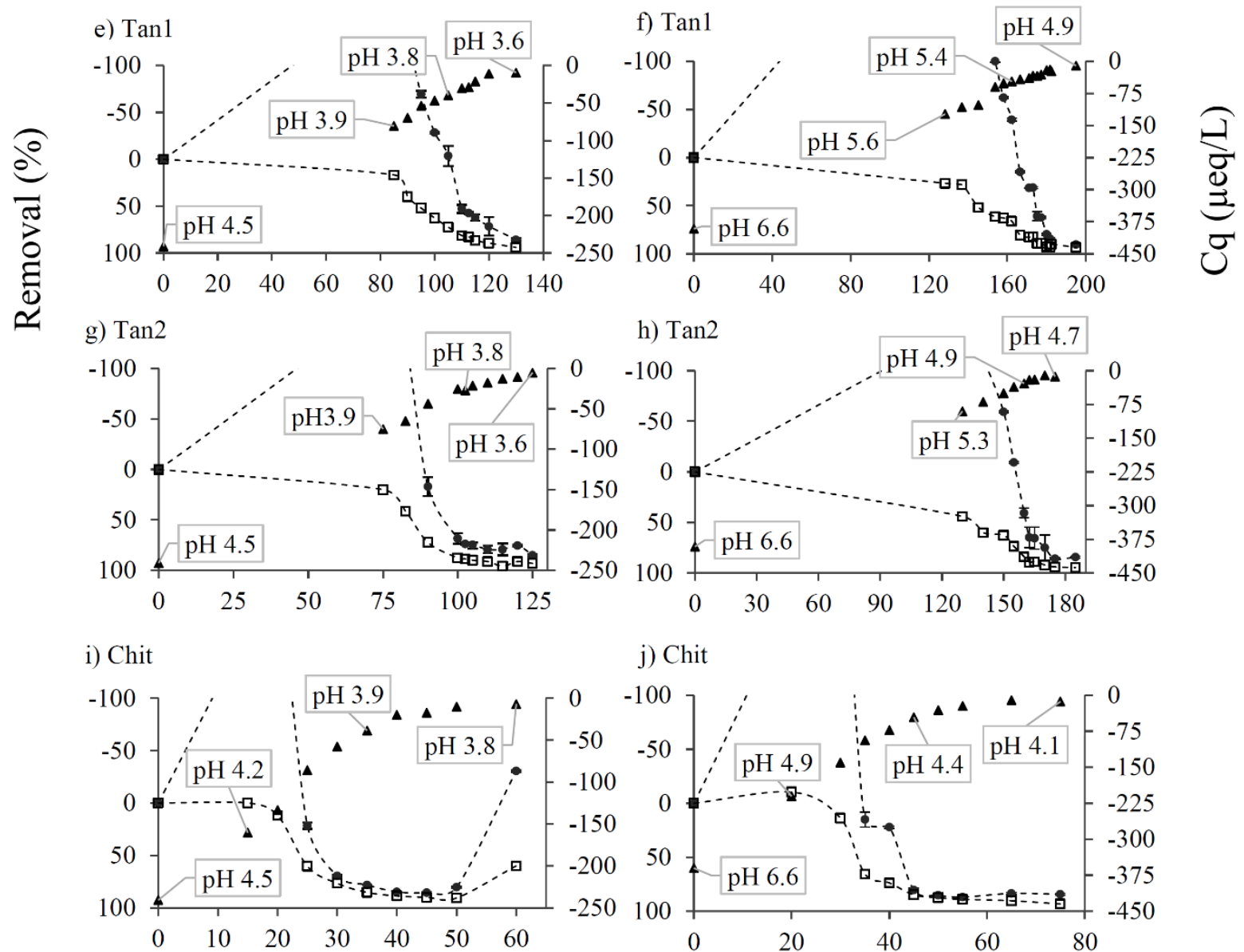

Dosage $(\mathrm{mg} / \mathrm{L})$

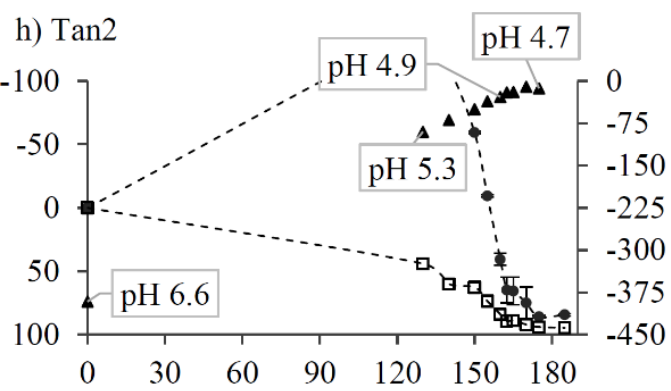

j) Chit

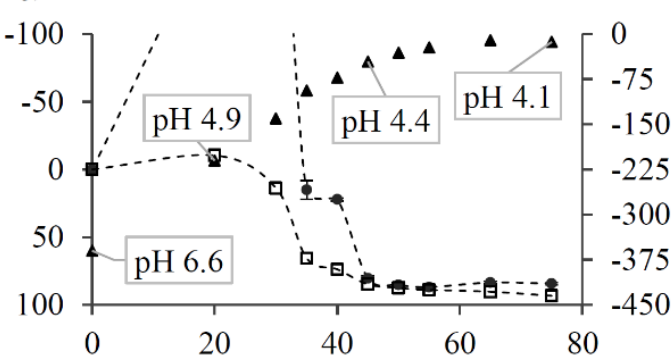

Dosage $(\mathrm{mg} / \mathrm{L})$

Figure 1 - Removal of turbidity (variation shown as error bars) and colour with increasing dosage of coagulant and the resulting residual charge quantity $(\mathrm{Cq})$ and $\mathrm{pH}$ of samples for initial water $\mathrm{pH} 4.5$ and 6.5 . 
The $\mathrm{pH}$ of peat extraction runoff water is reported to range between 4.5 and 7.0 (Heiderscheidt et al., 2015). Thus, the $\mathrm{pH}$ variations tested (4.5-6.5) reflected real operational conditions. The $\mathrm{pH}$ at which coagulation takes place is known to have a significant effect on coagulation and flocculation results. In natural waters, decreasing the water $\mathrm{pH}$ decreases the ionisation of carboxylic and phenolic functional groups of humic acids, resulting in a net decrease in negative charges and giving humic substances more hydrophobic characteristics (Bolto and Gregory, 2007). The clear influence of water $\mathrm{pH}$ on the charge characteristics of humic substances can be seen in the charge quantity (Cq) values measured in the raw water samples (Table 1). Besides influencing the physical and chemical characteristics of pollutant substances, $\mathrm{pH}$ also has a direct impact on coagulant properties and on the way it interacts with water and other substances (Bolto and Gregory, 2007; Slavik et al., 2012). At acidic pH, the hydrolysis species of metal salt coagulants are believed to be of a polymeric and more positive nature, thus improving their charge neutralisation capability (Bratby, 2006). The cationic charge of Chit is due to the presence of amine groups in the polymer chain. The protonation of these groups at low $\mathrm{pH}$ attributes the polymer a high cationic $\mathrm{CD}$, which decreases significantly at $\mathrm{pH} \geq 6$ (Renault et al., 2009). Therefore, at lower $\mathrm{pH}$, stronger interactions between the positively charged groups of Chit and negatively charged pollutants can be expected. According to the products suppliers, the cationic charges contained in the pDMAC and tannin polymers tested are the result of quaternary ammonium groups, so their $\mathrm{CD}$ should not be $\mathrm{pH}$ dependent. Nevertheless, in the case of pDMAC it has been suggested that the non-polar characteristics of its molecules facilitate their interaction with the more hydrophobic humic substances in acidic $\mathrm{pH}$ conditions (Kvinnesland and Odegaard, 2004). The humic nature of the runoff water samples was confirmed by the LC-OCD-OND fractionation results; which showed that over $70 \%$ of the DOC contained in the untreated samples was of a humic characteristics (Fig. 3). In the purification of acidic and humic waters, charge neutralization is believed to be the dominant coagulation mechanism (Kvinnesland and Odegaard, 2004; Kleimann et al., 2005; Bolto and Gregory, 2007). Thus, it follows that at lower $\mathrm{pH}$, lower coagulant dosages were required for effective coagulation (Fig. 1).

Best removal of colour and turbidity, was achieved by FS dosages which produced values of colloidal surface charges (Cq, Fig. 1) and $\zeta$-potential (Fig. 2) close to zero, emphasising the dominance of the charge neutralisation coagulation mechanism. Charge neutralization reactions are responsible not only for the removal of DOC but also for the removal of other charged compounds such as e.g., phosphatemetal-humic acid complexes. Effective coagulation via charge neutralisation has been found to occur at $\zeta$-potential values between -10 and $+5 \mathrm{mV}$ (Matilainen et al., 2010). Several studies have identified charge neutralisation as the main coagulation mechanism in the purification of humic waters by highCD polymers (Kvinnesland and Ødegaard, 2004; Libecki, 2010). However, a dominant charge neutralisation path cannot be drawn for pDMAC, the polymer with the highest CD. Although the residual 
total surface charge contained in samples treated with the pDMAC optimum dosages was low and only slightly negative (Fig. 1) the resulting $\zeta$-potential was lower than $-10 \mathrm{mV}$ (Fig. 2). Nevertheless, it is clear that charge neutralisation was an important factor in the destabilisation of the solution, although other mechanisms such as electrostatic patch and bridging occurred and played a significant role in the coagulation process. Charge neutralisation appears to have been the main mechanism of interaction for Chit, especially at lower initial pH (Fig. 2a). Samples treated by Chit optimum dosages showed $\zeta_{-}$ potential values between -10 and $-5 \mathrm{mV}$ and charge reversal was observed within the dosage range tested (Fig 2). In the case of Tan2, electrostatic interactions such as patch coagulation can be assumed to be the main mechanism since charge neutralisation can be mostly disregarded (Fig. 2) and the occurrence of bridging is unlikely due to the very low MW (Table 2) of the polymer (Bolto and Gregory, 2007).
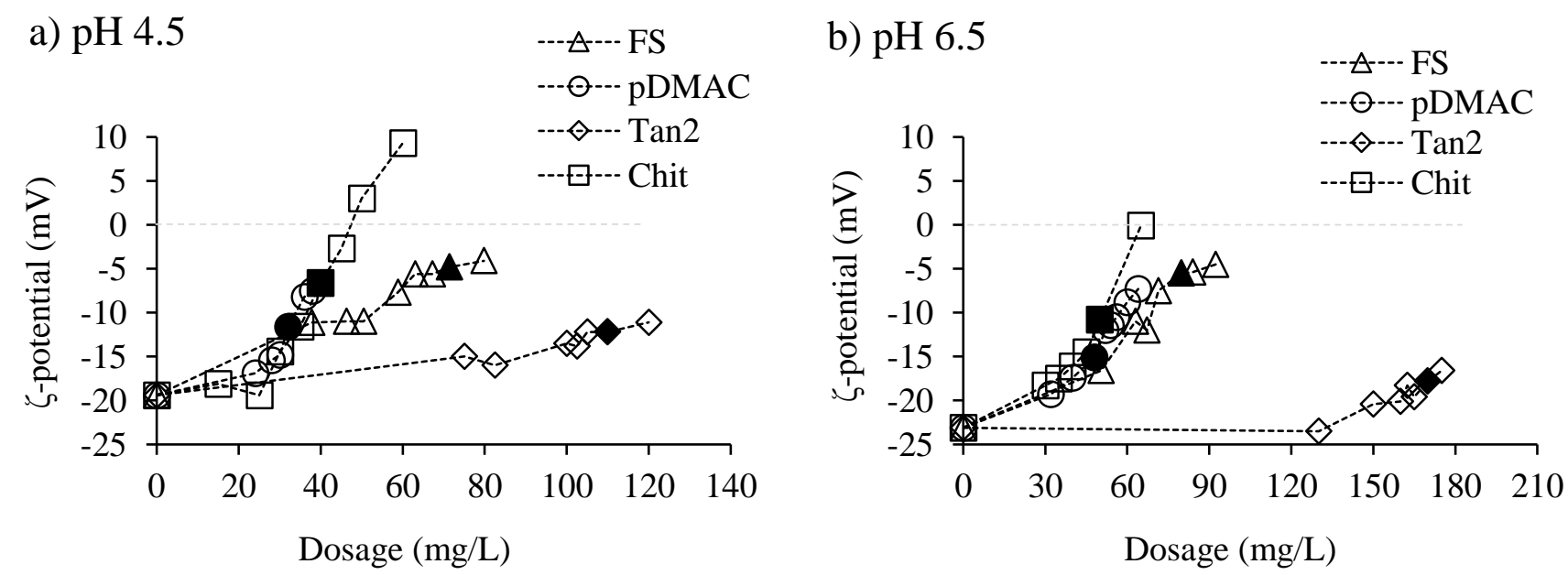

Figure 2 - Changes in $\zeta$-potential with the addition of increasing dosage of coagulant to raw water samples with (a) low initial $\mathrm{pH}$ (4.5) and (b) increased water $\mathrm{pH}$ (6.5) (optimum dosage represented by black-filled markers).

\subsection{Purification efficiency and LC-OCD-OND fractionation analysis}

\subsubsection{Overall purification efficiency}

In general, the purification efficiency achieved by the optimum dosage of the coagulants was very similar for both water $\mathrm{pH}$ (Table 3). FS achieved the best removal of DOC, tot-P, $\mathrm{PO}_{4}-\mathrm{P}$ and tot-N in the purification of both water samples. The removal of DOC (76-81\%) by FS was particularly high compared with that achieved by other coagulants (43-57\%). However, high residual $\mathrm{Fe}$ and $\mathrm{SO}_{4}{ }^{2-}$ concentrations were found in the purified water. Samples treated with Chit contained higher residual DOC (due to residual organic acid used in dissolution); but, Chit showed the best removal of SS (20$58 \%$ ). Significant increase in tot-N and $\mathrm{SO}_{4}{ }^{2-}$ concentrations were observed in samples treated with Tan2 (due to residual coagulant). All coagulants removed phosphorous (tot-P and $\mathrm{PO}_{4}-\mathrm{P}$ ) well with FS and 
pDMAC achieving the highest removal rates ( $>80 \%)$ followed by Chit $(>70 \%)$ and Tan2 (>55\%) (Table $3)$.

Table 3 - Water quality characteristics of raw water and samples treated with the optimum dosage of the coagulants, including \% removal of selected contaminants (concentrations shown as mean value \pm dev.

(deviation) between the two performed replicates).

\begin{tabular}{|c|c|c|c|c|c|c|c|c|c|}
\hline \multirow[b]{2}{*}{ Parameter } & \multirow{2}{*}{$\begin{array}{c}\text { Natural } \\
\text { sample } \\
(\mathrm{pH}=4.5)\end{array}$} & \multicolumn{2}{|c|}{ FS $71(\mathrm{mg} / \mathrm{L})$} & \multicolumn{2}{|c|}{ pDMAC 32 (mg/L) } & \multicolumn{2}{|c|}{ Tan2 $110(\mathrm{mg} / \mathrm{L})$} & \multicolumn{2}{|c|}{ Chit $40(\mathrm{mg} / \mathrm{L})$} \\
\hline & & $\begin{array}{c}\text { Residual } \\
\pm \text { dev. }\end{array}$ & $\begin{array}{c}\text { Removal } \\
(\%)\end{array}$ & $\begin{array}{l}\text { Residual } \\
\pm \text { dev. }\end{array}$ & $\begin{array}{c}\text { Removal } \\
(\%)\end{array}$ & $\begin{array}{c}\text { Residual } \\
\pm \text { dev. }\end{array}$ & $\begin{array}{c}\text { Removal } \\
(\%)\end{array}$ & $\begin{array}{l}\text { Residual } \\
\pm \text { dev. }\end{array}$ & $\begin{array}{c}\text { Removal } \\
(\%)\end{array}$ \\
\hline DOC (mg/L) & $76.2 \pm 2.0$ & $18.7 \pm 0.1$ & 76 & $32.4 \pm 0.0$ & 57 & $36.7 \pm 0.7$ & 52 & $43.4 \pm 0.6$ & 43 \\
\hline tot-P $(\mu \mathrm{g} / \mathrm{L})$ & $107 \pm 18.4$ & $14.0 \pm 0.0$ & 87 & $20 \pm 2.8$ & 81 & $31.5 \pm 2.1$ & 71 & $22.5 \pm 0.4$ & 79 \\
\hline $\mathrm{PO}_{4}-\mathrm{P}(\mu \mathrm{g} / \mathrm{L})$ & $34.5 \pm 3.5$ & $3.0 \pm 0.0$ & 91 & $2.5 \pm 0.7$ & 93 & $15.5 \pm 1.4$ & 57 & $10.5 \pm 0.7$ & 70 \\
\hline tot-N $(\mu \mathrm{g} / \mathrm{L})$ & $2300 \pm 141$ & $1150 \pm 71$ & 50 & $1600 \pm 0$ & 30 & $3950 \pm 71$ & -72 & $1450 \pm 71$ & 37 \\
\hline $\mathbf{S S}(\mathrm{mg} / \mathbf{L})$ & $7.5 \pm 2.5$ & $5.5 \pm 0.6$ & 27 & $4.1 \pm 1.5$ & 46 & $4.3 \pm 0.1$ & 43 & $3.1 \pm 1.1$ & 58 \\
\hline $\mathrm{Fe}(\mu \mathrm{g} / \mathrm{L})$ & $4400 \pm 141$ & $9050 \pm 71$ & -106 & $465 \pm 7$ & 89 & $285 \pm 7$ & 94 & $640 \pm 0$ & 85 \\
\hline $\mathrm{SO}_{4}^{2-}(\mathrm{mg} / \mathrm{L})$ & $4.9 \pm 0.2$ & $72.0 \pm 1.4$ & -1385 & $5.0 \pm 0.4$ & -3 & $12.0 \pm 0.0$ & -147 & $5.3 \pm 0.1$ & -9 \\
\hline Alkalinity $(\mathrm{mmol} / \mathrm{L})$ & $0.028 \pm 0.010$ & $0.001 \pm 0.000$ & & $0.001 \pm 0.000$ & & $0.001 \pm 0.000$ & & $0.001 \pm 0.000$ & \\
\hline SUVA (L/mg-m) & $3.8 \pm 0.1$ & $2.8 \pm 0.2$ & & $2.0 \pm 0.1$ & & $1.6 \pm 0.0$ & & $1.9 \pm 0.0$ & \\
\hline \multirow[t]{2}{*}{ pH } & $4.45-4.52$ & 3.3 & & 4.2 & & 3.8 & & 3.9 & \\
\hline & Natural & \multicolumn{2}{|c|}{ FS $80(\mathrm{mg} / \mathrm{L})$} & \multicolumn{2}{|c|}{ pDMAC $52(\mathrm{mg} / \mathrm{L})$} & \multicolumn{2}{|c|}{ Tan2 $170(\mathrm{mg} / \mathrm{L})$} & \multicolumn{2}{|c|}{ Chit 50 (mg/L) } \\
\hline Parameter & $\begin{array}{c}\text { sample } \\
(\mathrm{pH}=6.5)\end{array}$ & $\begin{array}{l}\text { Residual } \\
\pm \text { dev. }\end{array}$ & $\begin{array}{c}\text { Removal } \\
(\%)\end{array}$ & $\begin{array}{l}\text { Residual } \\
\pm \text { dev. }\end{array}$ & $\begin{array}{c}\text { Removal } \\
(\%)\end{array}$ & $\begin{array}{c}\text { Residual } \\
\pm \text { dev. }\end{array}$ & $\begin{array}{c}\text { Removal } \\
(\%)\end{array}$ & $\begin{array}{l}\text { Residual } \\
\pm \text { dev. }\end{array}$ & $\begin{array}{c}\text { Removal } \\
(\%)\end{array}$ \\
\hline DOC (mg/L) & $80.8 \pm 1.1$ & $15.6 \pm 0.3$ & 81 & $35.0 \pm 0.3$ & 57 & $38.0 \pm 0.1$ & 57 & $39.7 \pm 1.1$ & 51 \\
\hline tot-P $(\mu \mathrm{g} / \mathrm{L})$ & $115 \pm 7.1$ & $10.5 \pm 2.1$ & 91 & $20.5 \pm 0.7$ & 82 & $28.0 \pm 1.4$ & 76 & $24.0 \pm 0.0$ & 79 \\
\hline $\mathrm{PO}_{4}-\mathrm{P}(\mu \mathrm{g} / \mathrm{L})$ & $33.0 \pm 0.0$ & $2.5 \pm 0.47$ & 92 & $2.0 \pm 0.0$ & 94 & $13.5 \pm 0.7$ & 59 & $9.0 \pm 0.0$ & 73 \\
\hline tot-N $(\mu \mathrm{g} / \mathrm{L})$ & $2200 \pm 424$ & $1100 \pm 0$ & 50 & $2500 \pm 71$ & 7 & $5250 \pm 71$ & -139 & $1600 \pm 0$ & 27 \\
\hline $\mathrm{SS}(\mathrm{mg} / \mathrm{L})$ & $5.9 \pm 2.0$ & $4.8 \pm 2.2$ & 19 & $8.6 \pm 0.6$ & -46 & $4.6 \pm 1.6$ & 21 & $4.7 \pm 0.1$ & 20 \\
\hline $\mathrm{Fe}(\mu \mathrm{g} / \mathrm{L})$ & $4450 \pm 71$ & $5050 \pm 71$ & -13 & $390 \pm 57$ & 91 & $97 \pm 18$ & 98 & $405 \pm 7$ & 91 \\
\hline $\mathrm{SO}_{4}^{2-}(\mathrm{mg} / \mathrm{L})$ & $4.5 \pm 0.1$ & $72.5 \pm 0.7$ & -1529 & $5.0 \pm 0.0$ & -12 & $13.0 \pm 0.0$ & -192 & $4.9 \pm 0.1$ & -10 \\
\hline Alkalinity (mmol/L) & $0.380 \pm 0.050$ & $0.001 \pm 0.000$ & & $0.296 \pm 0.001$ & & $0.050 \pm 0.001$ & & $0.234 \pm 0.002$ & \\
\hline SUVA (L/mg-m) & $3.9 \pm 0.1$ & $2.1 \pm 0.0$ & & $2.1 \pm 0.0$ & & $1.3 \pm 0.0$ & & $2.4 \pm 0.0$ & \\
\hline pH & $6.52-6.70$ & 3.5 & & 5.3 & & 4.9 & & 4.3 & \\
\hline
\end{tabular}

\subsubsection{LC-OCD-OND fractionation analysis}

Lower DOC (20-30\%) concentrations were measured by the inline DOC analyser used during the LCOCD-OND fractionation experiments (Fig. 3) than by the in-house portable DOC analyser (Table 3). This might be due to the occurrence of in-container coagulation/flocculation during the transport and storage of samples resulting in the filtering out of organic substances prior to DOC fractionation analysis. Moreover, different analysers normally give different DOC results.

According to LC-OCD-OND results, about $5 \%$ of the DOC contained in the raw water samples $(\sim 2.8$ $\mathrm{mg} / \mathrm{L}$ ) was in the form of biopolymers (Fig. 3a and 3b, chromatograms in supplementary material). Biopolymers in this context are hydrophilic, high MW and non-ionic substances (Huber et al., 2011). All coagulants removed biopolymers well, with higher removal rates observed in the purification of samples with lower pH. This was particularly evident for Chit (Fig. 3a) which removed 85\% of biopolymers at $\mathrm{pH} 4.5$ and $55 \%$ at $\mathrm{pH}$ 6.5. The HS fraction, consisting mainly of humic and fulvic acids, made up the bulk of the DOC contained in the raw water samples $(\sim 41 \mathrm{mg} / \mathrm{L})$. In general, the HS fraction 
was more effectively removed by FS (85-91\%) with Tan2 showing the best removal (66-72\%) among the organic coagulants. When evaluating the characteristics of the humic substances (HS) fraction found in the raw water samples (molecularity $>750 \mathrm{~g} / \mathrm{mol}$ and $\mathrm{SAC} / \mathrm{OC} \approx 6$ ) against the diagram for natural waters presented by Huber et al. (2011), it follows that the HS contained were of pedogenic origin, i.e. it contained soil-derived fulvic acids. Furthermore, the samples contained high-MW aromatic humic compounds. Thus coagulation-flocculation can be regarded as an efficient method for the treatment of this type of water (Bolto and Gregory, 2007; Matilainen et al., 2010). The described diagram plots the SAC/OC ratio of the HS fraction against its nominal average MW expressed as molecularity. SAC (Spectral Absorption Coefficient) is the UV absorption detected at $254 \mathrm{~nm}$ wavelength (Huber et al., 2011).

a) $\mathrm{pH} 4.5$ replications $\mathrm{R} 1$ and $\mathrm{R} 2$



b) $\mathrm{pH} 6.5$ replications $\mathrm{R} 1$ and $\mathrm{R} 2$

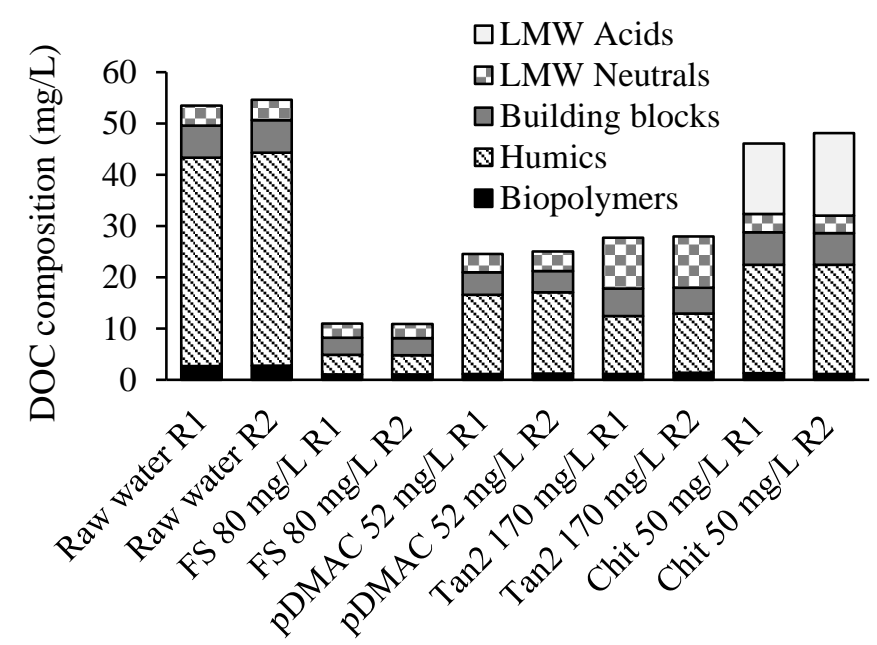

Figure 3 - Concentration of DOC fractions produced as a results of LC-OCD-OND fractionation of raw and treated water samples with (a) low initial pH (4.5) and (b) increased water $\mathrm{pH}$ (6.5) (two replicates at each $\mathrm{pH})$. 
An UVD response (supplementary material) was observed in the biopolymer fraction of FS-treated samples. The biopolymer fraction normally does not cause a response in UVD (no unsaturated structures). Furthermore, despite removing the majority of HS contained in the raw water samples, relatively high SUVA values were obtained for FS-treated samples (Table 3). This was probably due to high residual iron (Table 3). Iron is known to interfere with UV abs measurements (Weishaar et al., 2003) and thus the use of UV abs as an indicators of DOC fractions removed would not be reliable in this context.

The building blocks fraction is composed of breakdown products of HS. This fraction has previously been found not to be effectively removed by coagulation-flocculation (Bolto et al., 1999; Huber et al., 2011). Interestingly, some reduction was observed especially when FS was applied ( 46\%). The raw water samples did not contain LMW acids. However, around 30-45\% of residual DOC contained in Chittreated samples was composed of LMW acids (Fig. 3). This increase in LMW acid concentration can be attributed to the presence of acetic acid, which was used in the dissolution of the chitosan product. The LMW neutrals fraction of NOM contains alcohols, aldehydes, ketones, sugars and amino acids (Huber et al., 2011). Around 4-5 mg/L of LMW neutrals were present in the raw water samples and these were satisfactorily removed at initial water $\mathrm{pH} 4.5$, with FS being the most efficient (62\%). The concentration of LMW neutrals in samples treated with Tan2 was higher than that initially found in the raw water samples (Fig 3). The observed increase was due to residual coagulant. Tan2 is composed of very low MW polymeric chains which might display neutral characteristics in post-coagulation conditions (Fig. 1). This possibility was confirmed by the increased tot-N concentration (Table 3 ) and the occurrence of late eluting organic-bound (LMW neutrals) nitrogen found in Tan2-treated samples (Table 4).

The higher MW fractions (biopolymers and HS) were more efficiently removed by all coagulants tested, confirming previous findings (Bolto et al., 1999; Wand et al., 2013). The significantly higher removal rates shown by FS highlighted the importance of charge neutralisation in DOC removal via coagulationflocculation. However, the good HS removal rates achieved by Tan 2 emphasizes that charge neutralisation should not be considered as the only effective mechanism of HS removal. Higher MW fractions are generally the main precursor of DBP formation, especially when chlorine is applied (Zheng et al., 2015). However, low MW fractions have also been found to play a significant role in DBP formation being especially reactive with bromine and iodine (Hua and Reckhow, 2007). In this context, a suitable coagulant, for e.g. drinking water production, should achieve satisfactory removal of all DOC fractions.

Lee and Westerhoff (2006) found that the presence of organically-bound nitrogen (ON) does not influence the interactions between DOC and coagulant. Nevertheless, little information is available on 
ON removal during the coagulation-flocculation process. This study therefore also examined ON removal. Nitrogen is a limiting nutrient in aquatic ecosystems and nitrogenous substances can react with disinfectants to form carcinogenic compounds (Lee and Westerhoff, 2006). Therefore, increasing the knowledge regarding ON removal is an important factor in advancing the chemical purification method. Overall, ON fractions were most efficiently removed by FS (66-91\%) with Tan2 displaying the best removals (69-77\%) among the organic coagulants. The removal rates some extent reflected the biopolymer and HS removal patterns obtained by different coagulants (Fig. 3). The coagulation mechanisms responsible for organically-bound nitrogen removal can thus be assumed to be the same mechanisms described for DOC removal, for both FS and the organic polymers. Similar amounts $(\sim 0.3$ $\mathrm{mg} / \mathrm{L}$ ) of ON were linked to the biopolymer and HS fractions of the raw water samples (Table 4). In general, ON-biopolymers were more effectively removed (75-90\%) than the ON-humics (5-80\%) fraction. Lower inorganic-N (ammonium) residual concentration was found in Chit-treated samples (Table 4). The late ON fraction elution observed in Tan2-treated samples (supplementary material) overlapped the elution of inorganic nitrogen (ammonium). The inorganic fraction could not be separated and therefore, the ON-LMW neutrals fraction contained in Tan2-treated samples might have been slightly over-estimated.

Table 4 - Concentration of nitrogen fractions contained in the raw water and treated samples as a result of LC-OCD-OND fractionation (concentrations presented as mean value \pm dev. (deviation) between the two performed replicates).

\begin{tabular}{|c|c|c|c|c|}
\hline Sample & $\begin{array}{c}\text { ON-Biopolymers } \\
(\mu \mathrm{g} / \mathrm{L}) \pm \text { dev. }\end{array}$ & $\begin{array}{l}\text { ON-Humics } \\
(\mu \mathrm{g} / \mathrm{L}) \pm \text { dev. }\end{array}$ & $\begin{array}{c}\text { ON-LMW Neutrals } \\
(\mu \mathrm{g} / \mathrm{L}) \pm \text { dev. }\end{array}$ & $\begin{array}{c}\text { Inorganic-N } \\
(\text { Ammonium })(\mu \mathrm{g} / \mathrm{L}) \pm \mathrm{dev}\end{array}$ \\
\hline Raw water $\mathrm{pH} 4.5$ & $340 \pm 6$ & $362 \pm 133$ & No response & $868 \pm 43$ \\
\hline FS 71 (mg/L) & $39.0 \pm 2.8$ & $124 \pm 3$ & No response & $1008 \pm 116$ \\
\hline pDMAC $32(\mathrm{mg} / \mathrm{L})$ & $26.0 \pm 2.8$ & $235 \pm 57$ & No response & $900 \pm 8$ \\
\hline Tan2 $110(\mathrm{mg} / \mathrm{L})$ & Not quantifiable & $81.5 \pm 2.1$ & $3333 \pm 15$ & $\begin{array}{l}\text { Response overlaid by ON- } \\
\text { LMW Neutrals }\end{array}$ \\
\hline Chit 40 (mg/L) & $27.5 \pm 0.0$ & $243 \pm 15$ & No response & $315 \pm 62$ \\
\hline Raw water pH 6.5 & $305 \pm 3$ & $281 \pm 18$ & No response & $946 \pm 88$ \\
\hline FS $80(\mathrm{mg} / \mathrm{L})$ & $27.0 \pm 15.5$ & $54.0 \pm 4.2$ & No response & $979 \pm 19$ \\
\hline pDMAC $52(\mathrm{mg} / \mathrm{L}$ & $79.0 \pm 0.0$ & $241 \pm 71$ & No response & $900 \pm 62$ \\
\hline Tan2 170 (mg/L) & Not quantifiable & $87.5 \pm 34.6$ & $4936 \pm 15$ & $\begin{array}{l}\text { Response overlaid by ON- } \\
\text { LMW Neutrals }\end{array}$ \\
\hline Chit 50 (mg/L) & $76.5 \pm 2.1$ & $295 \pm 6$ & No response & Not quantifiable \\
\hline
\end{tabular}




\subsubsection{Settling characteristics of flocs formed}

The settling characteristics of the flocs formed is an important factors in evaluation of the coagulant performance. They represents the ability of the coagulant to provide flocs that can readily sediment, resulting in clarified supernatant water. Addition of all coagulants to both water samples resulted in a significant increase in the samples initial turbidity (6.9 NTU). The reported turbidity values for time ' 0 minutes' (Fig. 4) represent the turbidity measured at the end of the flocculation process (end of mixing, pre-sedimentation). Pre-sedimentation turbidity of over 70 NTU was observed in samples treated with FS and when pDMAC was added to water samples with higher initial pH (Fig. 4b). Chit and Tan2 displayed similar pre-sedimentation (time 0) turbidity values of around 30-40 NTU (Fig. 4). All coagulants achieved $\sim 95 \%$ removal of the pre-sedimentation turbidity after 25 min of settling. Overall, faster sedimentation rates were observed in treatment of the water samples with higher initial $\mathrm{pH}$; apart from flocs formed by pDMAC to which the opposite occurred (Fig. 4). Tan2 obtained the best settling characteristics achieving turbidity values lower than 5 NTU between $4(\mathrm{pH} 6.5)$ and $6 \mathrm{~min}(\mathrm{pH} \mathrm{4.5)}$ of sedimentation. FS also performed well, especially because its pre-sedimentation turbidity was substantially higher than that of the other coagulants. It achieved turbidity values of around 5 NTU between $11(\mathrm{pH} 6.5)$ and $13(\mathrm{pH} 4.5)$ of sedimentation. In terms of final water clarification, the lowest turbidity values (1-2 NTU) were found in samples treated with Chit and Tan2 regardless of the initial $\mathrm{pH}$ of the water.

$$
\text { a) } \mathrm{pH} 4.5
$$

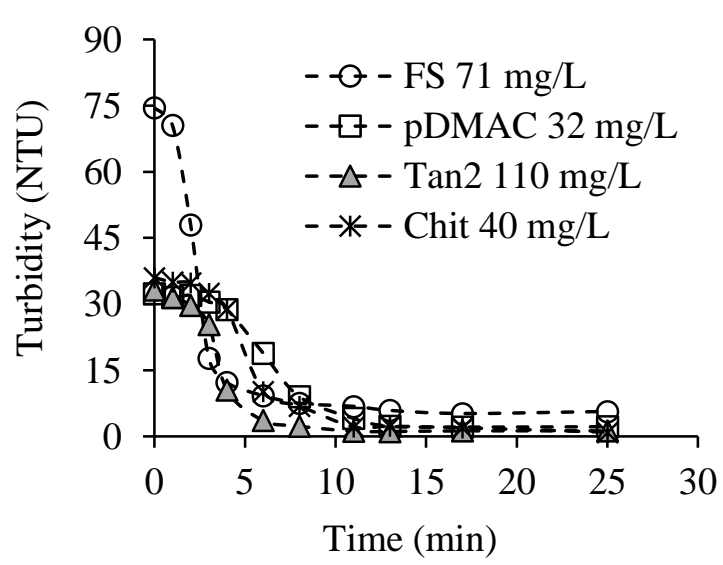

b) $\mathrm{pH} 6.5$

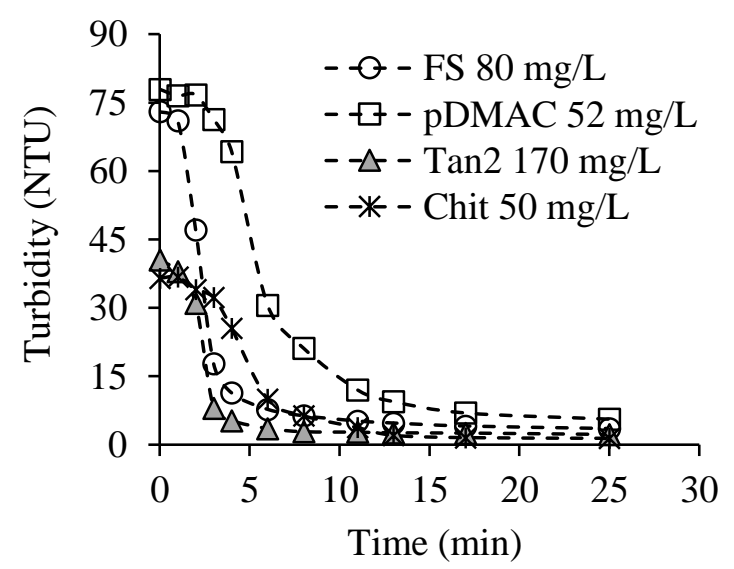

Figure 4 - Settling characteristics of flocs formed, removal of (pre-sedimentation) turbidity with time for samples with (a) low initial $\mathrm{pH}$ (4.5) and (b) increased water $\mathrm{pH}(6.5)$.

\subsubsection{Overall considerations regarding coagulant performance}

The higher overall purification efficiency achieved by FS (Table 3) can be attributed to its higher charge neutralisation capacity (Wei et al., 2009; Matilainen et al., 2010) and to the formation of insoluble 
hydrolysis products (pre-sedimentation turbidity over 70 NTU, Fig. 4). The formation of hydroxide precipitates can improve the coagulation/flocculation process by increasing the number of particles in suspension thus increasing particle collision frequency and enabling the occurrence of adsorption destabilisation and sweep mechanisms (Bratby 2006; Bolto and Gregory, 2007; Matilainen et al., 2010). This being especially beneficial for the type of natural water tested i.e. with relatively low turbidity. The benefits of the formation of metal hydroxide precipitates can be observed throughout the results obtained (Tables 3 and 4, Fig. 3). It can also be assumed to be the reason for the higher FS performance observed at $\mathrm{pH}$ 6.5. Regarding the efficiency of organic polymers, higher CD products generally performed better in terms of dosage (Fig. 1). However, a clear correlation between CD and purification efficiency could not be confirmed. While samples treated with pDMAC (highest CD) contained lower overall DOC and phosphorus residuals (Table 3), higher removal of SS and HS fraction (Fig. 3) was achieved by Tan2 (lowest CD). Chit (relatively high CD) performed well being more efficient in SS and tot-N removal than pDMAC, especially at lower $\mathrm{pH}$. According to visual observations made throughout the experimental phase, in comparison with other organic coagulants smaller flocs were formed by pDMAC, an effect which was more prominent at higher initial $\mathrm{pH}$. The formation of small flocs from interaction of high-CD polymers with humic waters under neutral $\mathrm{pH}$ conditions was also reported by Kvinnesland and Ødegaard (2004) and Libecki (2010). This could account for the observed increase in SS concentration in pDMAC-treated samples at pH 6.5 (Table 3) and for the poor settling characteristics displayed by the polymer (Fig. 4). A dual coagulant system where an organic polymers is dosed subsequently to FS should be explored. This would assure the presence of metal hydroxide precipitates potentially improving floc formation and SS removal. In addition, a dual coagulant system could result in lower dosage requirement for FS leading to lower Fe and acidity residual concentrations in the purified water than in samples treated with FS exclusively.

Relatively low SS removal efficiency $(<58 \%)$ was observed by all tested coagulants which is probably due to the experimental set-up. The optimum conditions (dosage, $\mathrm{pH}$, mixing, etc.) for SS and DOC removal normally differ from those required for DOC removal alone (Kvinnesland and Ødegaard, 2004; Matilainen et al., 2010). The conditions observed during our study (acidic $\mathrm{pH}$ and low turbidity water samples) to some extend favoured DOC over SS removal (Bratby, 2006; Bolto and Gregory, 2007; Matilainen et al., 2010). Furthermore, it is well known that floc formation and the resulting floc characteristics are significantly dependent on the hydraulic conditions applied upon and after coagulant addition (Sánchez-Martín et al., 2010; Slavik et al., 2012). Optimisation of mixing parameters to the specific requirements of a specific coagulant can result in flocs with improved settling characteristics and an overall improvement in coagulant performance. Significant variations in SS concentration (e.g. $5-70 \mathrm{mg} / \mathrm{L}$ ) typically occur at peat extraction sites where chemical purification is required (Heiderscheidt 
et al., 2015). It has been found that when particles are present, higher removal of NOM and turbidity can be achieved by metal salts and organic coagulants (Bolto et al., 2001). Evaluation of coagulants performance in the purification of particulate rich samples and the optimization of hydraulic condition for specific coagulants are recommended.

Regarding coagulant residual concentrations, the high DOC residual found in Chit-treated samples might be avoided by dissolution of Chit in other acids, e. g. hydrochloric or glutamic acid (Bratskaya et al., 2004). Chemically modified water soluble chitosan products have also been successfully studied (Yang et al., 2011; Chen et al., 2015). The high residual coagulant levels found in Tan2-treated samples point to over dosing in terms of colour removal. In this study, a combined requirement of colour and turbidity removal was imposed. During dosage requirement evaluations (Fig. 1), in particular for Tan2, satisfactory colour removal was obtained at substantially lower dosages than turbidity removal. Nevertheless, a suitable coagulant for the purification of peat extraction runoff water should be able to satisfactorily remove dissolved and particulate pollutants. Thus, the high required dosage and the occurrence of increased nitrogen concentration in Tan2-treated samples are important factors which restrict the application of the coagulant.

\section{Conclusions}

For the humic water tested, Chit and pDMAC required significantly lower dosage (40-55\%) than FS, while the tannin-based coagulants required substantially higher dosage (55-125\%). FS achieved the best removal of DOC, tot-P, $\mathrm{PO}_{4}-\mathrm{P}$ and tot- $\mathrm{N}$, but high residual $\mathrm{Fe}$ and $\mathrm{SO}_{4}{ }^{2-}$ concentrations were found in the purified water. Among the organic coagulants, pDMAC obtained the best removal of tot-P, $\mathrm{PO}_{4}-\mathrm{P}$ and DOC. However, it showed poor sedimentation characteristics at neutral $\mathrm{pH}$ (6.5) conditions. Chit and Tan 2 achieved the best removal of SS with flocs formed by Tan 2 displaying the best settling properties. Higher residual DOC concentrations were found in samples treated with Tan2 (coagulant residual) and Chit (might be avoided by dissolution in non-organic acid). Residual Tan 2 coagulant also resulted in an increased tot-N concentration in purified samples. The higher MW DOC fractions (biopolymers and HS) were more efficiently removed by all coagulants tested with FS being the most efficient. The significantly higher removal rates presented by FS highlighted the importance of charge neutralisation in DOC removal. However, good removals rates were also achieved by Tan2 (lowest CD polymer) indicating that charge neutralisation should not be considered as the only effective mechanism of HS removal.

In general, FS was the best performing coagulant, nevertheless the organic polymers demonstrated satisfactory performance with purification rates mostly inside the requirements set by environmental 
authorities for chemical purification of peat extraction runoff (COD 60-80\%, SS 50\%, tot-N 30-50\% and tot-P 60-90\%). Among the organic coagulants tested, Chit and pDMAC achieved good results in terms of dosage and purification efficiency. Thus, Chit and pDMAC have the potential to replace FS as the main coagulant agent in the purification of peat extraction runoff water. However, further research is required aiming at optimising process conditions for effective simultaneous removal of DOC and SS. Due to the high required dosage and increased nitrogen residual concentration observed in Tan2-treated samples, the tannin-based product cannot be considered a suitable coagulant for the application evaluated here. However, the use of Tan 2 in a dual coagulant system (FS + organic polymer) could be explored.

\section{Acknowledgements}

This research was supported by Maa-ja Vesitekniikan tuki r.y and Thule Institute. The authors would like to acknowledge the support received from the personnel at the Water Resources and Environmental Engineering and Chemical Process Engineering research units at the University of Oulu.

\section{References}

Ang, W.L., Mohannad, A.W., Teow, Y.H., Benamor, A., Hilal, H., 2015. Hybrid chitosan/FeCl3 coagulation-membrane processes: Performance evaluation and membrane fouling study in removing natural organic matter. Sep. Purif. Technol. 152, 23-31.

Bolto, B., Abbt-Braun, G., Dixon, D., Eldridge, R., Frimmel, F., Hesse, S., King, S., Toifl, M., 1999. Experimental evaluation of cationic polyelectrolytes for removing natural organic matter from water. Water Sci. Technol. 40, 71-79.

Bolto, B., Dixon, D., Eldridge, R., King, S., 2001. Cationic polymer and clay or metal oxide combination for natural organic matter removal. Water Res. 35, 2669-2676.

Bolto, B., Gregory, J., 2007. Organic polyelectrolytes in water treatment. Water Res. 41, 2301-2324.

Bratby, J., 2006. Coagulation and flocculation in water and wastewater treatment. $2^{\text {nd }}$ ed. London: IWA Publishing.

Bratskaya, S., Schwarz, S., Chervonetsky, D., 2004. Comparative study of humic flocculation with chitosan hydrochloride and chitosan glutamate. Water Res. 38, 2955-2961. 
Chen, Y-C., Wu, C-Y., Chung, Y-C., 2015. The coagulation characteristics of humic acid by using acidsoluble chitosan, water-soluble chitosan, and chitosan coagulant mixtures. Environ. Technol. 36, 11411146.

Evans, C.D., Monteith, D.T., Cooper, D.M., 2005. Long-term increases in surface water dissolved organic carbon: Observations, possible causes and environmental impacts. Environ. Pollut. 137, 55-71.

Finnish Environmental Institute, 2015. The formation of peat extraction related water pollution and its management opportunities - Final report of the SulKa project. Reports of the Finnish Environmental Institute 23/2015. (Finnish with English abstract). www.syke.fi/publications|helda.helsinki.fi/syke (accessed 15.02.2016).

Finnish Ministry of the Environment, 2015. Guidelines for environmental protection in peat mining. (Finnish with English abstract). https://helda.helsinki.fi/bitstream/handle/10138/155221/OH_2_2015.pdf?sequence=1 （accessed 15.02.2016).

Graham, N., Gang, F., Fowler, G., Watts, M., 2008. Characterization and coagulation performance of a tannin-based cationic polymer: A preliminary assessment. Colloid. Surface. A 327, 9-16.

Guibal, E., Van Vooren, M., Dempsey, B.A., Roussy, J., 2006. A review of the use of chitosan for the removal of particulate and dissolved contaminants. Separ. Sci. Technol. 41, 2487-2514.

Harford, A.J., Hogan, A.C., Jones, D.R., van Dam, R.A., 2011. Ecotoxicological assessment of polyelectrolyte flocculant. Water Res. 45, 6393-6402.

Heiderscheidt, E., Leiviskä, T., Kløve, B., 2015. Chemical treatment response to variations in non-point pollution water quality: results of a factorial design experiment. J. Environ. Manage. 150, 164-172.

Heiderscheidt, E., Leiviskä, T., Ronkanen, A-K., Kløve, B., 2016. Evaluating the suitability of synthetic organic polymers to replace iron salts in the purification of humic and sediment-rich runoff. Desalination Water Treat. 57, 10948-10957.

Holme, K.R., Perlin, A.S., 1997. Chitosan N-sulfate: a water soluble polyelectrolyte. Carbohyd. Res. $302,7-12$.

Hua, G., Reckhow, D., 2007. Characterization of disinfection byproduct precursors based on hydrophobicity and molecular size. Environ. Sci. Technol. 41, 3309-3315. 
Huber, S.A., Balz, A., Albert, M., Pronk, W., 2011. Characterisation of aquatic humic and non-humic matter with size-exclusion chromatography e organic carbon detection e organic nitrogen detection (LCOCD-OND). Water Res. 45, 879-885.

Jeong, S., Sathasivan, A., Kastl, G., Shim, W.G., Vigneswaran, S., 2014. Experimental investigation and modeling of dissolved organic carbon removal by coagulation from seawater. Chemosphere 95, 310316.

Kleimann, J., Gehin-Devald, C., Auweter, C., Borkovec, M., 2005. Super-stoichiometric charge neutralization in particle-polyelectrolyte systems. Langmuir 21, 3688-3698.

Kurita, K., Kamiya, M., Nishimura, S., 1991. Solubilization of a rigid polysaccharide: controlled partial $\mathrm{N}$-acetylation of chitosan to develop solubility. Carbohyd. Polym. 16, 83-88.

Kvinnesland, T., Ødegaard, H., 2004. The effects of polymer characteristics on nano particle separation in humic substances removal by cationic polymer coagulation. Water Sci. Technol. http://www.ncbi.nlm.nih.gov/pubmed/1568602050, 185-91.

Lee, W., Westerhoff, P., 2006. Dissolved organic nitrogen removal during water treatment by aluminum and cationic polymer coagulation. Water Res. 40, 3767-3774.

Letterman, R.D., Pero, R.W., 1990. Contaminants in polyelectrolyte used in water treatment. J. Am. Water Works Assoc. 82, 87-97.

Libecki, B., 2010. The effectiveness of humic acid coagulation with the use of cationic polyacrylamides. Water Sci. Technol. 61, 1555-1560.

Matilainen, A., Vepsäläinen, M., Sillanpää, M., 2010. Natural organic matter removal by coagulation during drinking water treatment: A review. Adv. Colloid Interfac. 159, 189-197.

Nozaic, D.J., Freese, S.D., Thompson, P., 2001. Long term experience in the use of polymeric coagulants at Umgeni Water. Water Sci. Technol. 1, 43-50.

Oladoja, N.A., 2015. Headway on natural polymeric coagulants in water and wastewater treatment operations. J. Water Process Eng. 6, 174-192.

Renault, F., Sancey, B., Badot, P-M., G. Crini, G., 2009. Chitosan for coagulation/flocculation processes - An eco-friendly approach. Eur. Polym. J. 45, 1337-1348. 
Sánchez-Martín, J., González-Velasco, M., Beltrán-Heredia, J., 2010. Surface water treatment with tannin-based coagulants from Quebracho. Chem. Eng. J. 165, 851-858.

Slavik, I., Muller, S., Mokosch, R., Azongbilla, A., Uhl, W., 2012. Impact of shear stress and pH changes on floc size and removal of dissolved organic matter (DOM). Water Res. 46, 6543-6553.

Slavik, I., Farias, J., Uhl, W., 2014. Coagulation process control by applying a semi-empirical model to predict DOC-removal on the basis of LC-OCD-analytics. In: Proc. IWA World Water Congress, Lisbon/Portugal, September 21-26 (2014).

Song, T., Pranovich, A., Sumerskiy, I., Holbom, B., 2008. Extraction of galactoglucomannan from spruce wood with pressurised hot water. Holzforschung, 62, 659-666.

Tramontini, M., Angiolini, L., 1994. Mannich Bases. Chemistry and Uses. CRC Press, Boca Raton.

Vuorenmaa, J., Forsius, M., Mannio, J., 2006. Increasing trends of total organic carbon concentrations in small forest lakes in Finland from 1987 to 2003. Sci. Total Environ. 365, 47-65.

Wang, D., Zhao, Y., Xie, J., Chow, C.W.K., Leeuwen, J.V., 2013. Characterizing DOM and removal by enhanced coagulation: A survey with typical Chinese source waters. Sep. Purif. Technol. 110, 188-195.

Wei, J., Gao, B., Yue, Q., Wang, Y., Li, W., Zhu, X., 2009. Comparison of coagulation behaviour and floc structure characteristic of different polyferric-cationic polymer dual-coagulants in humic acid solution. Water Res. 43, 724-732.

Weishaar, J. L., Aiken, G. R., Bergamaschi, B. A., Fram, M. S., Fujii, R., Mopper, K., 2003. Evaluation of specific ultraviolet absorbance as an indicator of chemical composition and reactivity of dissolved organic carbon. Environ. Sci. Technol. 37, 4702-4708.

Wichmann A., 2015. Vapo Oy. VS: SULKA data and some help needed [private email]. Sent: 17/07/2015 10:38 o'clock (GMT + 0200).

Yang, Z., Shang, Y., Lu, Y., Chen, Y., Huang, X., Chen, A., Jiang, Y., Gu, W., Qian, X., Yang, H., Cheng, H., 2011. Flocculation properties of biodegradable amphoteric chitosan-based flocculants. Chem. Eng. J. 172, 287-295.

Zheng, D., Andrews, R.C., Andrews, S.A., Taylor-Edmonds, L., 2015. Effects of coagulation on the removal of natural organic matter, genotoxicity, and precursors to halogenated furones. Water Res. 70, 18-129. 
